\title{
A simulation-based study evaluating the preparedness of interns' post-anaesthesia rotation in managing a failed obstetric intubation scenario: Is our training good enough?
}

\author{
I Kiwalabye, ${ }^{1} \mathrm{MB}$ ChB, DA (SA); L Cronjé, ${ }^{1} \mathrm{MB}$ ChB, FCA (SA); S Schoeman, ${ }^{2} \mathrm{MB}$ ChB, MMEd (Medical education), PhD, FHEA (UK); \\ T Sommerville, ${ }^{1} \mathrm{MB}$ ChB, DA (SA), FFA (SA), BSc (Med), MEd, PhD \\ ${ }^{1}$ Discipline of Anaesthesiology and Critical Care, Nelson R Mandela School of Medicine, University of KwaZulu-Natal, Durban, South Africa \\ ${ }^{2}$ Lead for Assessment, Kent and Medway Medical School, Canterbury, UK
}

Corresponding author: I Kiwalabye (i.kiwas@gmail.com)

Background. Difficult or failed intubation of obstetric patients may be up to 8 times higher than in general surgical patients. A decline in obstetric intubation opportunities may be a contributing factor, resulting in reduced training opportunities for junior doctors, who therefore do not acquire airway management skills.

Objectives. To assess post-anaesthesia rotation interns' preparedness to manage a difficult/failed obstetric airway scenario.

Methods. We recruited 49 interns, obtained informed consent and individually assessed them on a simulation-based scenario using a highfidelity manikin. Two independent assessors scored participants using a checklist assessment and a global rating scale. After the simulationbased scenario, participants completed a questionnaire on their internship training, rated the simulation experience and received debriefing. The borderline regression method was used to determine the checklist pass mark.

Results. Analysis showed that $40 \%$ of interns passed. Correlation between assessors was strong for checklist scores and global ratings. The main reasons for failing were repeated attempts at intubation and failure to optimise the intubating position or conditions. There was concern regarding the infrequent use of a supraglottic airway device as a rescue. Twenty-eight interns had performed $<5$ general obstetric anaesthetic procedures.

Conclusions. There are concerns regarding adequate anaesthetic preparation for interns to manage a difficult/failed intubation scenario in a full-term pregnancy. Despite the Essential Steps in Managing Obstetric Emergencies (ESMOE) airway module training, which all interns should receive, a high rate of success was not achieved in this study. Simulation-based training and assessment may be a valuable tool to improve intern training and preparedness.

S Afr Med J 2021;111(3):265-270. https://doi.org/10.7196/SAMJ.2021.v111i3.14443

The difficult airway is a clinical situation that includes the concepts of failed intubation, difficult laryngoscopy and difficult mask ventilation. ${ }^{[1]}$ The incidence of failed or difficult intubation in obstetric general anaesthesia (GA) patients ranges from 1:443 to $1: 220$, a rate up to 8 times that found in general surgical patients, ${ }^{[2-6]}$ although lower incidences have been described, possibly in highvolume obstetric units. ${ }^{[7,8]}$

Factors known to lead to increased difficulty with obstetric airway management include: pregnancy-associated physiological changes, onset of labour, which has also been shown to be associated with increased Mallampati scores and subsequently increased difficulty with intubation, loss of airway skills due to an increased number of caesarean sections done under neuraxial anaesthesia, and emergency cases managed by junior staff outside normal working hours. . $^{[4-6,9-12]}$ In response to this situation, the Difficult Airway Society (DAS) released an algorithm (2015), specifically for difficult obstetric airway management. ${ }^{[12]}$

In South Africa (SA), junior doctors graduating from medical school are required to complete 2 years of internship, 2 months of which are spent rotating through an anaesthesia department. During this time, interns should develop skills to administer GA and regional anaesthesia. They are then expected to use these skills during their community service year, which is often completed without adequate supervision or further training, at rural and district hospitals..$^{[13,14]}$
The Essential Steps in Managing Obstetric Emergencies (ESMOE) guidelines were developed to equip doctors in the management of obstetric emergencies, including an airway module and an algorithm for the difficult obstetric airway. ${ }^{[15]}$ The Saving Mothers 2014 - 2016: Seventh Triennial Report on Confidential Enquiries into Maternal Deaths in South Africa noted that district hospitals contributed to the majority (56\%) of anaesthesia-related deaths. Of 87 such deaths, $35 \%$ were as a result of respiratory failure due to poor airway management. ${ }^{[16]}$

The primary objective of this study was to determine if interns who have completed their anaesthetic rotation are prepared to manage a simulated difficult airway in the obstetric patient. The secondary objectives were: $(i)$ to gain insight into current airway management experience during their rotation; and (ii) to develop a valid checklist assessment tool that might be used for future evaluation of interns' preparedness for community service.

\section{Methods}

\section{Study design and participants}

Preliminary power analysis was based on our anticipated percentage pass/fail. There were no similar studies found to provide a reference point; we therefore used a 50\% pass/fail split. Employing a twotailed test, we calculated the sample size using an alpha value of 0.05 and a beta value of 0.2 , with a statistical power of 0.8 . Based on these statistical parameters and assuming our sample was a true 
representation of the entire population, a sample size of $N=49$ was calculated.

Convenience sampling was done by communicating with the various anaesthesia departments and inviting the interns to participate in the study. Only interns who had completed their anaesthetic rotation and signed informed consent were included in the study.

Interns were recruited in 3 groups from 4 hospitals in the greater Durban area (between 1 January and 30 June 2018). Each group of interns gathered at the Inkosi Albert Luthuli Central Hospital (IALCH) Simulated Modules in Anaesthesia and Resuscitation Training (SMART) centre, where quantitative data were collected through a scenario-based simulation scored from a checklist and from a questionnaire (Tables 1 and 2).

At the simulation laboratory, each candidate was assessed on their ability to manage an unanticipated difficult airway in an obstetric patient. This occurred using a scenario-based simulation ('can't intubate but can ventilate' scenario) on a high-fidelity manikin. The manikin was computer operated to mimic human physiology; haemoglobin oxygen saturation would be affected, depending on whether the manikin was successfully ventilated. The manikin's tongue was inflated to prevent visualisation of vocal cords and successful intubation prior to the candidate attempting to intubate.

The scenario presented to the participants was a 38 -year-old primigravida at 38 weeks' gestation booked for an elective caesarean section due to cephalopelvic disproportion, but who did not consent to spinal anaesthesia despite adequate counselling. The interns were informed that there was a senior anaesthetic consultant available on the premises. The scenario was chosen to simulate a situation that may typically arise at a district/regional hospital.

Each group of interns was initially briefed: they would have to manage an airway problem (no further details were provided) and were then familiarised with the manikin, anaesthesia machine and airway equipment. They were given the opportunity to mask ventilate and intubate the manikin without any modifications to the airway, which all the interns were able to demonstrate. Each participant was then individually assessed by 2 specialist anaesthetists, who scored the scenario simultaneously but independently without discussion, using a checklist assessment based on the DAS algorithm for the obstetric patient. After all participants had been assessed, they were gathered as a group and debriefed on the scenario. A questionnaire was then completed.

\section{Measurement methods}

The checklist assessment was based on elements extracted from the DAS guidelines for the management of a difficult obstetric airway. An initial checklist assessment marksheet was created and sent to 3 experts in the department; items were weighted based on their feedback. The assessment comprised two components, a checklist score and a global rating scale (GRS) (Table 1). A full mark was allocated for each task only if it was successfully completed by the candidate. The different weighted tasks on the checklist resulted in a total score of 31 , with oxygenation having the highest mark (half of the total).

Any candidate who made $>2$ attempts at intubation failed, irrespective of whether they achieved the pass mark. In this study, an attempt at intubation was defined as the action of inserting a laryngoscope, terminating with successful placement of the endotracheal tube or removal of the laryngoscope and the recommencement of bag-valve-mask (BVM) ventilation. The latter was included, because both the DAS obstetric airway guideline and ESMOE algorithm allow only 2 attempts at intubation, with a third attempt to be performed only by a senior doctor. This avoids multiple attempts, causing airway trauma that might lead to a 'can't intubate, can't ventilate' scenario. ${ }^{[12]}$

The GRS was used to obtain an overall impression of the candidate's performance, as candidates might achieve the minimum score and pass the scenario but might have managed the scenario poorly. The borderline regression method of standard setting was applied, using each assessor's numerical checklist score and their global rating of the candidate to determine the pass mark for this assessment. ${ }^{[17]}$

\section{Statistical analysis}

The data were captured on an Excel spreadsheet (Microsoft Corp., USA), and SPSS version 24/25 (IBM Corp., USA) was used to analyse the data.

Incidences of categorical variables were calculated and reported as number and percentage. Binary outcome variables were presented as $n, \%$, with $95 \%$ confidence intervals (CIs), where appropriate. Differences were compared using Fisher's exact test.

\begin{tabular}{ll} 
Table 1. Checklist assessment marksheet with score and global rating scale & \\
\hline Items & Marks, $\boldsymbol{n}$ \\
\hline Pre-oxygenation & 5 \\
Optimising patient position & 3 \\
Induction & 2 \\
Cricoid pressure & 1 \\
Intubation attempt & 5 \\
Maintain saturation after 1st attempt & 3 \\
(BVM or SAD use was noted by assessor) & 1 \\
Optimisation before 2nd attempt & 3 \\
Recognise failed intubation & 2 \\
Declare failed intubation & 5 \\
Call for senior help & \\
Maintain saturation after 2nd attempt & \\
(BVM or SAD use was noted by assessor) & \\
Global rating scale & \\
\hline Excellent & \\
BVM = bag-valve-mask; SAD = supraglottic airway device. & \\
&
\end{tabular}




\begin{tabular}{|c|c|}
\hline Questions & $\begin{array}{l}\text { Participants, } \\
n(\%)\end{array}$ \\
\hline \multicolumn{2}{|l|}{ Year of internship } \\
\hline 1st & $19(39)$ \\
\hline 2nd & $30(61)$ \\
\hline \multicolumn{2}{|l|}{ Base hospital } \\
\hline Prince Mshiyeni Memorial & $17(35)$ \\
\hline King Edward & $16(33)$ \\
\hline R K Khan & $10(20)$ \\
\hline Addington & $6(12)$ \\
\hline \multicolumn{2}{|l|}{ Undergraduate university } \\
\hline Witwatersrand & $7(14)$ \\
\hline KwaZulu-Natal & $13(27)$ \\
\hline Cape Town & $7(14)$ \\
\hline Stellenbosch & $5(10)$ \\
\hline Pretoria & $4(8)$ \\
\hline Free State & $4(8)$ \\
\hline Sefako Makgatho Health Sciences & $4(8)$ \\
\hline Walter Sisulu & $3(6)$ \\
\hline Foreign trained & $1(2)$ \\
\hline Not specified & $1(2)$ \\
\hline \multicolumn{2}{|l|}{ Regional anaesthesia experience, $n$} \\
\hline$<30$ & $13(27)$ \\
\hline $30-90$ & $30(61)$ \\
\hline$>90$ & $6(12)$ \\
\hline \multicolumn{2}{|l|}{ General anaesthesia experience, $n$} \\
\hline$<5$ & $28(57)$ \\
\hline $5-10$ & $13(27)$ \\
\hline$>10$ & $8(16)$ \\
\hline \multicolumn{2}{|l|}{ ESMOE training } \\
\hline Yes & $26(53)$ \\
\hline No & $23(47)$ \\
\hline \multicolumn{2}{|l|}{ Airway course training } \\
\hline Yes & $9(18)$ \\
\hline No & $40(82)$ \\
\hline \multicolumn{2}{|l|}{ How would you rate your performance? } \\
\hline Excellent & $0(0)$ \\
\hline Good & $11(22)$ \\
\hline Fair & $28(57)$ \\
\hline Poor & $10(20)$ \\
\hline \multicolumn{2}{|l|}{ Did you find the scenario realistic? } \\
\hline Yes & $47(96)$ \\
\hline No & $2(4)$ \\
\hline \multicolumn{2}{|c|}{$\begin{array}{l}\text { Do you feel that internship training helped to } \\
\text { prepare you to handle the scenario? }\end{array}$} \\
\hline Yes & $47(96)$ \\
\hline No & $2(4)$ \\
\hline
\end{tabular}

Pearson's correlation coefficient analysis was used to investigate the level of agreement between the 2 assessors in their checklist marking and global judgements. The borderline regression method was used to determine the pass mark for the assessment.

\section{Ethical approval}

Ethical approval was obtained from the University of KwaZulu-Natal
Biomedical Research Ethics Committee (ref. no. BE079/17) and the KwaZulu-Natal Department of Health (ref. no. KZ_20107_001).

\section{Results}

A total of 49 interns participated in the study (none of those who had been approached declined). The distribution of participants between the 4 hospitals was 17, 16, 10 and 6, respectively (Table 2).

\section{Checklist assessment scores}

The borderline regression method was applied to the data for both assessors. This determined a pass mark of 19/31 for assessor 1 (A1) and 18/31 for assessor 2 (A2); using their combined data, the pass mark was $19 / 31$ (Fig. 1). The pass rate for the scenario for participants assessed by A1 was 61.3\% (30/49; 95\% CI 47.5 - 74.8) and for A2, $65.3 \%$ (32/49; 95\% CI 51.9 - 78.6), based only on the checklist score process.

Fig. 2 depicts the scores per assessor, noting clustering and level of agreement in the distribution. The Pearson correlations between A1 and $\mathrm{A} 2$ was found to be $r=0.94$ for the checklist scores and $r=0.79$ for the global rating scores.

\section{Additional passing criteria}

Forty-eight percent (24/49) of candidates made a third attempt at intubation. After taking into account candidates who had passed on the checklist mark but who made $>2$ attempts at intubation, those who passed decreased to $38.7 \%$ (19/49; 95\% CI 25.2 - 52.4) for A1 and $40.8 \%(20 / 49 ; 95 \%$ CI 27.0 - 54.5) for A2. Averaging the results of the 2 assessors, based on the score and the number of intubations performed, $40 \%$ of the candidates passed.

\section{Checklist-itemised performance}

The percentages of participants who passed individual items on the checklist assessment are indicated in Table 3 (values presented as $n / N, \%$ and $95 \% \mathrm{CI}$ ). Only $61 \%$ of interns considered doing a rapid sequence induction. Prior to both the first and second attempts at intubation, $14 \%$ and $26 \%$, respectively, considered optimising patient position or intubating conditions. Maintenance of oxygenation fell to $77 \%$ after the second attempt and assessors noted that only $14 \%$ of participants used a supraglottic airway device (SAD).

We did not calculate a correlation between those who passed/ failed the scenario and the number of GAs they performed, as we felt the number of GAs claimed by a minority of the candidates was not plausible (range 10 - 50) during their 2-month rotation. There was no correlation between those who passed or failed and their attendance of ESMOE (Fisher exact test 0.567).

\section{Discussion}

The main findings of our study were that only $40 \%$ of the interns passed. The majority did not identify failed intubation, with only $38 \%$ declaring a failed intubation and $43 \%$ calling for help from a senior doctor. This resulted in multiple attempts at intubation without optimising intubating conditions or focusing on oxygenation, resulting in the pass rate decreasing and potentially worse patient outcomes.

Our study has highlighted the following concerns in key performance areas of managing a difficult obstetric intubation: (i) only two-thirds considered doing a rapid sequence induction, despite evidence that pregnant patients from 16 weeks' gestation are an aspiration risk; ${ }^{[18]}$ (ii) very few interns optimised patient position or intubating conditions, as suggested in the DAS algorithm, to improve intubating success; (iii) oxygenation was less likely to 


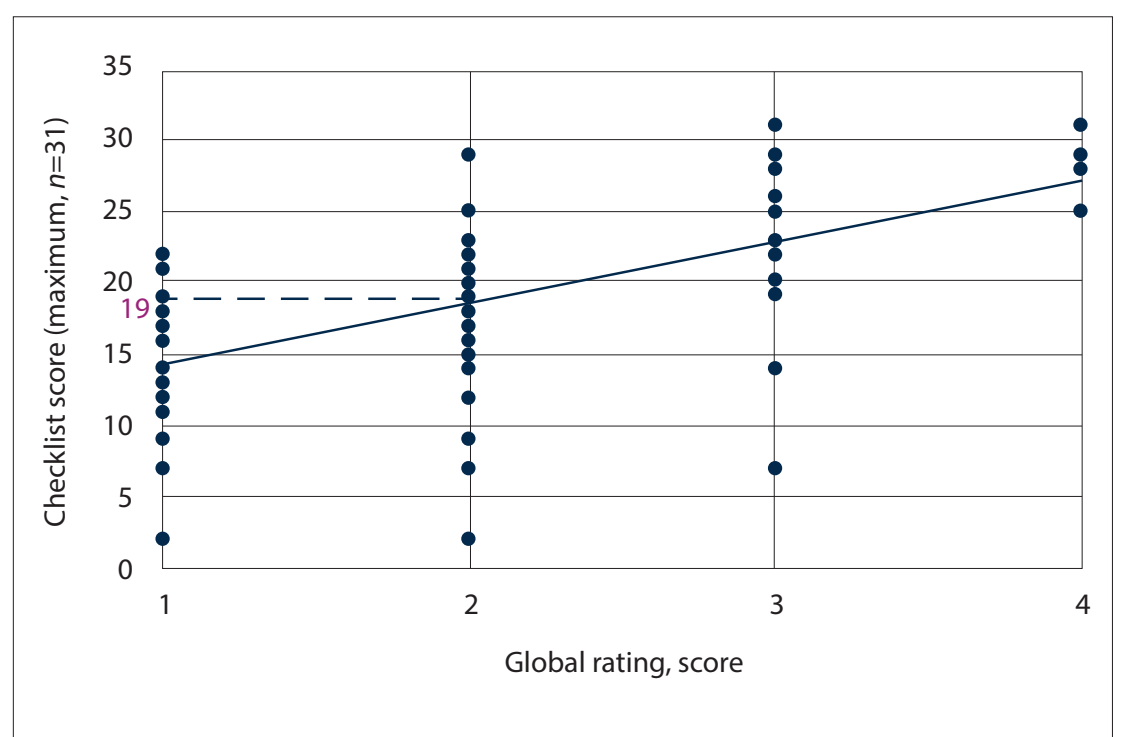

Fig. 1. Illustration of the borderline regression method used to set the pass mark. Global ratings used were: $1=$ fail, $2=$ borderline, $3=$ pass, $4=$ excellent.

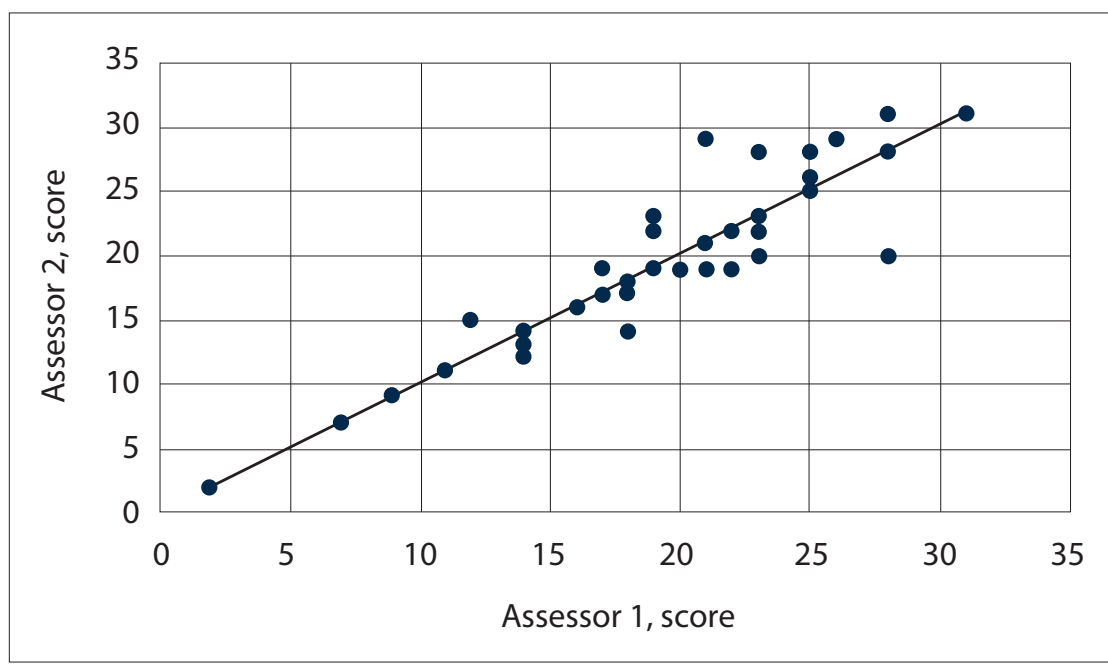

Fig. 2. Examiner checklist correlation ( $\mathrm{r}=0.94$ ) (total for checklist, $\mathrm{N}=31$ ).

be maintained with successive attempts at intubation; (iv) only $14 \%$ ever considered $\mathrm{SAD}$ as an oxygenation rescue device; and $(v)$ almost half attempted a third intubation, thus showing fixation error and obsession with 'getting the tube in' at all costs, rather than oxygenating by other means.

The MBRRACE-UK (Mothers and Babies: Reducing Risk through Audits and Confidential Enquiries across the UK) report of 2014 showed that fixation error contributed to the death of a pregnant patient, whereby other alternatives were not considered in the management of a difficult airway. ${ }^{[19]}$ The risks of fixation error is highlighted in the well-publicised case of Elaine Bromiley, who died as a result of hypoxic brain injury due to senior anaesthetists persisting with multiple intubation attempts for 20 minutes, while her haemoglobin oxygen saturation remained shown that in hospitals where trainees administered more GAs, the incidence of failed intubation decreased and difficult airways were managed appropriately. ${ }^{[7]}$ Senior supervising doctors are also likely to take over management of such a scenario without involving the interns, as reported by our interns.

Interestingly, the vast majority (96\%) of the interns felt that their internship training adequately prepared them to manage the scenario, showing a gap between their perception of adequacy and what the literature has shown regarding their subsequent experience or preparedness as community service doctors (CSDs). Compared with other medical domains through which they had rotated, Nkabinde et al. ${ }^{[22]}$ found that CSDs felt less knowledgeable and able to manage anaesthesia, especially anaesthesia-associated emergencies. According to Kusel et al.. ${ }^{[23]}$ a large proportion of CSDs did not feel comfortable administering GA, despite considering their internship as being adequate, and concluded that intern training should be adjusted to meet the needs of CSDs. In a follow-up article, Kusel et al. ${ }^{[24]}$ stated that 'it is reasonable to assume that their lack of obstetric anaesthesia experience is a significant contributing factor to anaesthesia-related morbidity and mortality' The Saving Mothers 2014 - 2016: Seventh Triennial Report on Confidential Enquiries into Maternal Deaths in South Africa $^{[16]}$ showed that most anaesthetic deaths occurred at district level hospitals, where most anaesthetics are performed by CSDs, with $35 \%$ of deaths as a result of poor airway management. The lack of preparedness of interns is compounded by inadequate supervision and training of doctors providing anaesthetics in district level hospitals and rural settings. ${ }^{[13,14]}$

The ESMOE programme was adapted in SA from the Life Saving Skills - Emergency Obstetric and Newborn Care programme in 2008 to improve the quality of care that obstetric patients receive by equipping doctors with the skills to manage obstetric emergencies. ${ }^{[25]}$ Interns are required to attend ESMOE training during their anaesthetics and obstetrics and gynaecological rotations. The anaesthesia course manual contains information on airway assessment and an algorithm for the management of a difficult airway. In a before-and-after observational study assessing the impact of ESMOE training on maternal deaths in SA (January 2011 - December 2016), it was found that despite an overall improvement in maternal outcomes, no significant improve- 


\begin{tabular}{|c|c|c|c|}
\hline & Assessor 1 & Assessor 2 & Composite \\
\hline Item & $\begin{array}{l}\text { Participants }(N=49) \text {, } \\
n(\% ; 95 \% \mathrm{CI})\end{array}$ & $\begin{array}{l}\text { Participants }(N=49) \text {, } \\
n(\% ; 95 \% \mathrm{CI})\end{array}$ & $\begin{array}{l}\text { Average of assessors } \\
1 \text { and } 2, \%\end{array}$ \\
\hline Pre-oxygenation & $47(95 ; 90-101)$ & $47(95 ; 90-101)$ & 95 \\
\hline Optimising patient position & $5(10 ; 2-19)$ & $9(18 ; 8-29)$ & 14 \\
\hline Induction & $48(97 ; 94-101)$ & $46(93 ; 87-100)$ & 95 \\
\hline Cricoid pressure & $31(63 ; 50-77)$ & $31(63 ; 50-77)$ & 63 \\
\hline Intubation attempt* ${ }^{*}$ & $49(100)$ & $49(100)$ & 100 \\
\hline $\begin{array}{l}\text { Maintain saturation after } 1 \text { st attempt } \\
\text { (BVM or SAD use was noted by assessor) }\end{array}$ & $43(87 ; 79-97)$ & $43(87 ; 79-97)$ & 87 \\
\hline Optimisation before $2 \mathrm{nd}$ attempt & $11(22 ; 11-34)$ & $14(29 ; 16-41)$ & 26 \\
\hline Recognise failed intubation & $23(46 ; 32-61)$ & $24(50 ; 35-63)$ & 48 \\
\hline Declare failed intubation & $18(37 ; 23-50)$ & $19(39 ; 25-52)$ & 38 \\
\hline Call for senior help & $21(43 ; 29-57)$ & $21(43 ; 29-57)$ & 43 \\
\hline $\begin{array}{l}\text { Maintain saturation after } 2 \text { nd attempt }^{*} \\
\text { (BVM or SAD use was noted by assessor) }\end{array}$ & $38(79 ; 66-89)$ & $37(76 ; 63-88)$ & 77 \\
\hline
\end{tabular}

ment after saturation training was shown for anaesthetic-related complications $(p=0.481) .{ }^{[25]}$ In our study, it was demonstrated that there was no correlation between those who passed our scenario and whether they attended ESMOE training.

The ESMOE difficult airway algorithm and that of the DAS are similar, i.e. they limit the number of intubations to 2 , encourage use of a laryngeal mask airway should intubation fail, and use of front-ofneck access in a 'can't intubate and can't ventilate' scenario. However, the DAS guideline places greater emphasis on preplanning, use of nasal oxygenation or gentle mask ventilation during induction, use of a second-generation laryngeal mask airway, and limiting insertion attempts with a laryngeal mask airway to 2 . The DAS guideline also provides factors to consider regarding when to wake a patient should intubation fail. ${ }^{[12,15]}$ Our study suggests that poor performance in these areas may require amendment of the ESMOE airway algorithm and/or incorporation of the DAS guideline, with a change in emphasis during teaching and methods of training.

Appropriate standardised tools should be developed to assess the performance of interns on common anaesthetic obstetric emergencies, such as those for the management of spinal hypotension and cardiac arrest. ${ }^{[26]}$ We used elements of the DAS difficult obstetric airway algorithm as a basis for our study, where the assessed items were weighted in conjunction with local experts to yield the checklist assessment. There were strong correlations between the 2 assessors' checklist scores and their global ratings, thus supporting the reliability of the assessment data.

A possible solution for interns to gain the necessary experience and skills to manage a difficult airway during their anaesthetic rotation would be to include simulation training. It has been shown that use of simulation training helps with adherence to difficult airway algorithms. ${ }^{[27]}$ A study by Hubert et al. ${ }^{[28]}$ showed improved acquisition of algorithms and procedural skills, as well as retention of these skills for up to a year. An SA study by Moodley and Gopalan ${ }^{[29]}$ found that interns who had been taught to use simulation performed better and showed greater participant satisfaction than those who had received didactic lectures. ${ }^{[29]}$ Simulation has also been shown to help with the development of non-technical skills, such as task management, teamwork, situational awareness and decision-making. ${ }^{[27]}$ There are conflicting results regarding highfidelity v. low-fidelity simulation training, but the consensus is that any simulation training is an invaluable tool. ${ }^{[30]}$ Simulation can also be used to demonstrate competency regarding a specific skill or management of a scenario, as demonstrated in our study. The majority of candidates (95\%) felt that simulation was helpful and many felt that it was worth incorporating as part of the internship training.

\section{Study limitations}

As the data collection covered a 6-month period, with 3 groups being assessed at 2-month intervals, there was potential for interns to discuss the scenario with candidates who were still to be recruited and for the various institutions to change their way of teaching. To mitigate this possibility, interns were told to keep the details of the scenario confidential.

Our sampling technique, although convenient, limited external validity.

Improvements to the assessment checklist would be to remove whether the candidate recognises that they are in a 'can't intubate but can ventilate' scenario, as this was difficult to assess; a more objective assessment would be that they declare a failed intubation during the scenario. Secondly, candidates who perform $<2$ intubations should be given weighted points, and those who perform $>2$ intubations should be allocated zero, thus incorporating the additional failing criteria into the checklist marksheet and simplifying data analysis.

\section{Conclusions}

As junior doctors make the transition from internship to community service - mostly performed in rural regional/district level hospitals - it is important that they are equipped with the necessary skills and training to perform GA and manage any subsequent complications. Our study raised concerns that internship training might not adequately prepare interns to manage the difficult obstetric airway that we simulated. While in this study we tried to refine our assessment tool to make it more valid, further studies comparing various levels of anaesthetic providers and their performance would help to validate it. Simulation training should help with the retention of difficult airway algorithm drills and would provide a safe environment for practising scenarios, such as the 'can't intubate but can ventilate' scenario, which may not be encountered during their 2-month rotation but is important for their future patients. 
Declaration. The research for this study was done in partial fulfilment of the requirements for IK's MMed (Anaesthesia) degree at the University of KwaZulu-Natal, Durban, SA.

Acknowledgements. We thank Dr D Pillay, who assisted with data collection, and Mr N Bhimsan for the use of the UKZN SMART centre. Author contributions. IK and LC contributed to the study design, data analysis and write-up, and TS and SS to the data analysis and write-up of the manuscript.

Funding. None.

Conflicts of interest. None.

1. Rudra A. Airway management in obstetrics. Ind J Anaesth 2005;49(4):328-335.

2. Samsoon GL, Young JR. Difficult tracheal intubation: A retrospective study. Anaesthesia 1987;42(5):487-490. https://doi.org/10.1111/j.1365-2044.1987.tb04039.x

3. Kinsella SM, Winton AL, Mushambi MC, et al. Failed tracheal intubation during obstetric general anaesthesia: A literature review. Int J Obstet Anesth 2015;24(4):356-374. https://doi.org/10.1016/j. ijoa.2015.06.008

4. Rahman K, Jenkins J. Failed tracheal intubation in obstetrics: No more frequent but still managed badly. Anaesthesia 2005;60(2):168-171. https://doi.org/10.1111/j.1365-2044.2004.04069.x

5. Barnardo P, Jenkins J. Failed tracheal intubation in obstetrics: A 6-year review in a UK region. Anaesthesia 2000;55(7):690-694. https://doi.org/10.1046/.j.1365-2044.2000.01536.x

6. Quinn AC, Milne D, Columb M, Gorton H, Knight M. Failed tracheal intubation in obstetric anaesthesia: 2 yr national case-control study in the UK. Br J Anaesth 2013;110(1):74-80. https://doi. anaesthesia: 2 yr nation
org $/ 10.1093 /$ bja/aes 320

7. Djabatey E, Barclay P. Difficult and failed intubation in 3430 obstetric general anaesthetics. Anaesthesia Djabatey E, Barclay P. Difficult and failed intubation in 3430 obstetric gener

8. Rocke D, Murray W, Rout C, Gouws E. Relative risk analysis of factors associated with difficult intubation in obstetric anesthesia. Anesthesiology 1992;77(1):67-73. https://doi.org/10.1097/00000542199207000-00010

9. Pilkington S, Carli F, Dakin MJ, et al. Increase in Mallampati score during pregnancy. Br J Anaesthesia 1995;74(6):638-642. https://doi.org/10.1093/bja/74.6.638

0. Kodali BS, Chandrasekhar S, Bulich LN, Topulos GP, Datta S. Airway changes during labor and delivery. Anesthesiology 2008;108(3):357-362. https://doi.org/10.1097/ALN.0b013e31816452d3

11. Vasdev GM, Harrison BA, Keegan MT, Burkle CM. Management of the difficult and failed airway in obstetric anesthesia. J Anesthesia 2008;22(1):38-48. https://doi.org/10.1007/s00540-007-0577-z

12. Mushambi MC, Kinsella SM, Popat M, et al. Obstetric Anaesthetists' Association and Difficult Airway Society guidelines for the management of difficult and failed tracheal intubation in obstetrics. Airway Society guidelines for the management of difficult and failed trac

13. Theron A, Rout C. 'Safe anaesthesia' for the South African rural obstetric patient in KwaZulu-Natal. South Afr J Anaesthesia Analg 2014;20(6):233-237. https://doi.org/10.1080/22201181.2014.983717
14. Lamacraft G, Kenny P, Diedericks B, Joubert G. Training and experience of doctors administering obstetric anaesthesia in the Free State level 1 and 2 hospitals. South Afr J Anaesthesia Analg 2008:14(2):13-17.

15. ESMOE guidelines. Essential Steps in the Management of Obstetric Emergencies. 2011. esmoe.coza/ download/guidelines-on-maternity-care-in-sa-pdf-2/ (accessed 14 January 2021).

16. Pattison R, ed. Saving Mothers 2014 - 2016: Seventh Triennial Report on Confidential Enquiries into Maternal Deaths in South Africa. Pretoria: National Department of Health, 2018.

17. Loh K-Y, Nurjahan MI, Ong KK, Roland GS, Noor AR. OSCE Standard Setting by Borderline Regression Method in Taylor's Clinical School. Singapore: Springer, 2016.

18. Bedson R, Riccoboni A. Physiology of pregnancy: Clinical anaesthetic implications. Cont Educ Anaesth Crit Care Pain 2014;14(2):69-72. https://doi.org/10.1093/bjaceaccp/mkt036

19. Kurinczuk J, Draper E, Field D, et al. Experiences with maternal and perinatal death reviews in the UK - the MBRRACE-UK programme. Br J Obstet Gynaecol 2014;121(S4):41-46. https://doi. org/10.1111/1471-0528.12820

20. Bromiley M. The case of Elaine Bromiley. Clin Human Factors 2005:1-18. https://www.chpso.org/sites/ main/files/file-attachments/nhs_human_factors.pdf? 1449074836 (accessed 26 January 2021).

21. Farina Z, Rout C. 'But it's just a spinal': Combating increasing rates of maternal death related to spinal anaesthesia. S Afr Med J 2013;103(2):81-82. https:///doi.org/10.7196/sami.6308

22. Nkabinde T, Ross A, Reid S, Nkwanyana N. Internship training adequately prepares South African medical graduates for community service - with exceptions. S Afr Med J 2013;103(12):930-934. https://doi.org/10.7196/SAMJ.6702

23. Kusel B, Farina Z, Aldous C. Practising anaesthesia as a community service doctor: A survey-based assessment. South Afr J Anaesth Analg 2017;23(2):45-49. https://doi.org/10.1080/22201181.2017.1318483

24. Kusel B, Farina Z, Aldous C. Creating the perfect intern anaesthesia rotation: A survey using feedback from past interns. South Afr J Anaesth Analg 2017;23(2):34-39. https://doi.org/10.1080/22201181.2 017.1305192

25. Pattinson RC, Bergh A-M, Ameh C, et al. Reducing maternal deaths by skills-and-drills training in managing obstetric emergencies: A before-and-after observational study. S Afr Med J 2019;109(4):241-245, https://doi.org/10.7196/samj.2019.v109i4.13578

26. Horsten G, Wise R, Ramroop S, Rodseth R. The development of a scoring tool for the measurement of performance in managing hypotension and intra-operative cardiac arrest during spinal anaesthesia for caesarean section. South Afr J Anaesth Analg 2015;21(3):63-69. https://doi.org/10.1080/222011 81.2015.1054617

27. Chang C-H. Medical simulation is needed in anesthesia training to achieve patient's safety. Korean J Anesthesiol 2013;64(3):204. https://doi.org/10.4097/kjae.2013.64.3.204

28. Hubert V, Duwat A, Deransy R, Mahjoub Y, Dupont H. Effect of simulation training on compliance with difficult airway management algorithms, technical ability, and skills retention for emergency cricothyrotomy. Anesthesiology 2014;120(4):999-1008. https://doi.org/10.1097/ ALN.0000000000000138

29. Moodley T, Gopalan D. Airway skills training using a human patient simulator. South Afr J Anaesth Analg 2014;20(3):147-151. https://doi.org/10.1080/22201173.2014.936778

30. Munshi F, Lababidi H, Alyousef S. Low- versus high-fidelity simulations in teaching and assessing clinical skills. J Taibah Univ Med Sci 2015;10(1):12-15. https://doi.org/10.1016/j.jtumed.2015.01.008

Accepted 19 October 2020. 